\title{
GeoSurv II Unmanned Aerial Vehicle: A major undergraduate project with multidisciplinary teams
}

\author{
Alan Steele, PhD P.Eng. \\ Associate Professor, \\ Dept. of Electronics, \\ Carleton University \\ asteele@doe.carleton.ca
}

\author{
Jeremy Laliberté, PhD PEng \\ Assistant Professor, \\ Dept. of Mechanical \& Aerospace. Eng. \\ Carleton University \\ jlaliber@mae.carleton.ca
}

\begin{abstract}
A final year undergraduate capstone design project was run in 2010-2011 and involved 32 students, 8 lead engineers and a project manager. The project was to design, develop and build an unmanned aerial vehicle (UAV) that can be used for geophysical surveying and was carried out in the Department of Mechanical and Aerospace Engineering at Carleton University. It built upon previous years work and involved students mostly from the Aerospace Engineering and Mechanical Engineering BEng programs. However, there was cross-department input, with students from the BEng programs Computer and Systems Engineering, Software Engineering and Communication Engineering, who undertook their final year project working on the avionics. Students were split into groups with lead engineers guiding the groups and individuals, plus there was an overall project manager. The groups were aerodynamics, avionics, flight test, integration and structures. The lead engineers were faculty, sessional lecturers and one graduate student teaching assistant. Sessional lecturers brought experience from the military and government research laboratories. Individual groups met weekly and additionally all students from all groups met collectively, again weekly, to share and discuss progress and issues. Students were required to produce design reports, as well as a group final report and each term a formal design review. Besides the development of GeoSurv II a new UAV design, named Corvus, was started and 10 students, drawn from across the different groups, worked on the preliminary design with the aim to produce a demonstrator vehicle. This paper describes the organization and running of such a large, multidisciplined group project as well as giving details of student opinions taken throughout the project's progress over the academic year.
\end{abstract}

\section{Introduction}

Since 1999 large final year team projects have been a standard feature of the BEng. programs offered in the Dept. of Mechanical and Aerospace at Carleton University [1]. The design of first an aircraft [2] and later unmanned aerial vehicles (UAV) [3] has been offered as projects, primarily for students on the Aerospace Eng. BEng. program since 1992. By rolling the design forward annually the projects have become multi-year design projects.

These mandatory large team projects usually involve around 30 students making them larger than the typical group project team size average of 3.3 reported in the 2007 survey by Vincent and Wild [4]. Running such a project requires additional management and organization over a smaller group project that are typically managed by a single Faculty member. One benefit is that a more ambitious project can be undertaken.

In this paper we describe a project to develop a UAV, called GeoSurv II, designed for aerial geomagnetic surveying in collaboration with Sander Geophysics Ltd. As well, a smaller UAV group was spun-off from the main team to focus on designing a next-generation vehicle, a demonstrator of a multi-role UAV, called Corvus, in collaboration with Brican Flight Systems. The focus of this paper will be on the management and organization as well as reporting student opinions from surveys carried out during the two project terms.

\section{Group Structure and Management}

The overall project team comprised of 32 students, who were separated in to groups as detailed in Table 1. Each group had at one or more lead engineers, and there was an overall project manager. Lead engineers were five faculty members, one sessional (ex- 
military), two researchers (from the National Research Council) and one graduate teaching assistant. The project manager was a faculty member.

Besides the dedicated functional groups designated in Table 1. Another group was formed from a few members from each of the listed groups. The task of this derivative group was to develop a demonstrator for the next UAV, named Corvus.

Table 1. Project groups

\begin{tabular}{|c|c|}
\hline Group & Number of Students \\
\hline Aerodynamics & 6 \\
\hline Avionics & 6 \\
\hline Design Integration & 2 \\
\hline Flight Test & 6 \\
\hline Structures & 12 \\
\hline
\end{tabular}

\subsection{Group Tasks and Organization}

Each group was tasked with work related to their area and each member of the group was given an individual role and set of tasks developed with their lead engineer. Example responsibilities of the different groups were:

- Aerodynamics - Aspects of aerodynamic performance of the UAV including propeller, wings, flaperons and tail or empennage.

- Avionics - Electrical battery power, control electronics, servos, wiring, radio control and flight termination system.

- Design Integration - Air vehicle documentation and certification, configuration and weight control, project management, documentation, drawings and web page control.

- Flight test - Engine performance, general flight readiness, maintenance, taxi and flight test planning.

- Structures - Vehicle construction including, fuselage, wings, undercarriage, empennage and structural health monitoring.

Management of the group was up to the group's lead engineer(s). This overall splitting into sections with group leaders and an overall project manager provided a organization model similar to what may be found in industry.

Individual students were responsible for keeping track of their time spent on project work and reporting this regularly to lead engineers through time sheets.
The Corvus cross-functional group comprised of a number of students from each team and reported primarily to a lead engineer for Corvus (who was also the overall project manager). As that teams members worked on the conceptual design and the developmental vehicle, they would report back to their own 'home' team to give updates as well as receive input and ideas.

\subsection{Group Communication}

There were regular mandatory weekly meetings at both the group level and at the overall project level. Group meetings, chaired by lead engineers, focused on individual progress whereas the project level meetings, chaired by the project manager, gave a chance for the group to report progress. The weekly project meetings were attended by all involved in the project and within the meeting a representative from each group presented slides summarizing the weekly items to report. It was also a forum for lead engineers and students from other groups to raise questions and discuss the design and construction of the UAV. The team meeting typically lasted 2 to $2 \frac{1}{2}$ hours.

Each group had a student designated as the group liaison who was the first point-of-contact person for inter-group communication. This ensured a clear responsibility for guiding enquiries to the right person in a group. The liaison also had to report to the Design Integration group for items such as major design changes, work schedules, task breakdowns and conflict resolution between groups (if any).

Extensive use of the internet was made with the use of e-mail, online document system, a shared project drive and a web page. Access was made available to the reports and documentation that had been written in previous years projects, as this year's work built upon a design and a constructed prototype.

Restricted access laboratory space was provided and had to be organized and maintained by students. Control was exercised over equipment and procedures for assembly and disassembly of the vehicle as well as the construction techniques. Workshop manufacture of parts involved scheduling and some of the manufacture was done by appropriately trained students.

\section{Project Deliverables and Assessment}

The two vehicles being developed each had their own specifications and goals. In 2010-11 GeoSurv II was building upon an existing design and Corvus was to produce a preliminary design and flight demonstrator. 


\subsection{Overall Goals}

For GeoSurv II a set of major objectives was established by the project manager and given to the all the team at the start of the project [5]. These included:

- implementation of some structural health monitoring

- redesigned of empennage and boom

- new all-composite landing gear

- review servo power requirements and battery selection

- complete ground and flight testing of prototype

The Corvus UAV was at a preliminary design phase and some of that group's goals were:

- develop vehicle outer mould-line for use with computational fluid dynamics analysis and wind tunnel testing,

- propulsion system selection

- avionics system architecture design

\subsection{Design Reports}

As the groups pursued the goals of the project, there was a requirement to write technical design reports (DRs) on discrete aspects of the work. This provided documentation and a record of the various aspects of the UAV's design and operation. DRs could detail design choices, analysis results, results of testing, structural drawing or wiring schematics. Each document was assigned a unique number, provided by the Design Integration team and before final approval each DR was required to be read and approved by another student. Although it varied from student to student depending on the work undertaken, commonly students wrote two or three reports a term. The DRs were not a replacement for the final report, but obviously were useful when writing that report. Writing DRs as soon as possible was encouraged to avoid the 'back-loading' of the writing process to the the later stages of the project time. For future teams the repository of DRs would become a central resource to understand the decisions, analysis and testing made earlier.

The continuous documenting of work done, through DRs, was a process that made the project similar to work undertaken in industry.

\subsection{Design Reviews}

Besides the use of DRs and the final report to document the design process there were also two major presentations, one each term, when every student would report planned work or work completed. These were done as formal design reviews. The first review in November focused on the proposed work, along with some early completed work, and was presented to an internal groups of assessors, mostly the team leaders.

The second and final design review in March was mostly a summary of findings and achievements. It was also a chance to show the final state of the prototype or demonstrator vehicles. This review was attended and assessed by a range of people from industry and government.

Both of the design reviews were marked and marks were taken from the external guests as well as the lead engineers.

\subsection{Marking}

The marking scheme was provided to the students at the outset [5] and consisted of

- Oral presentations $25 \%$ (10\% Fall, $15 \%$ Winter $)$

- Performance evaluations 40\% (15\% Fall, 25\% Winter)

- Winter term report $35 \%$

Performance evaluations were done by the lead engineers and, as stated to students, was based upon "quality and quantity of work, team performance and leadership" [5].

\subsection{Project Achievements}

Despite not getting to a final flight stage the project did progress and a number of key outcomes were achieved, for GeoSurv II these included:

- Engine testing on test frame.

- Low speed taxi test, Figure 1, (high-speed taxi test had to be abandoned due to bad weather).

- Design of all-composite main landing gear.

- Structural health monitoring of empennage boom with strain gauges.

- New flaperon servo selection, purchase and testing.

- Updating of the full avionics system including, batteries, radio control programming, sensors and wiring interconnections.

Figure 1. Preparation for GeoSurv II low speed taxi test.

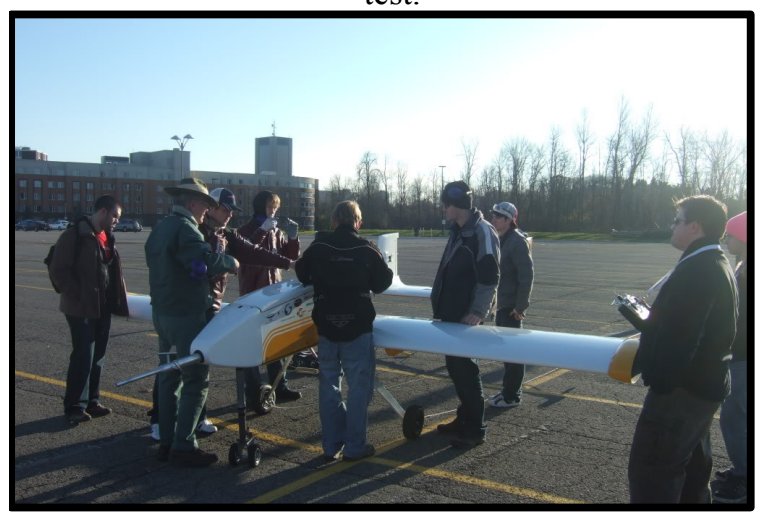


Corvus had similar success including:

- A full basic design for the demonstrator

- Construction of the internal fuselage, Figure 2.

- Wind tunnel testing of wing models.

- Selection and procurement of open hardware avionic system.

Figure 2. Fuselage internal structure for Corvus -Rook demonstrator

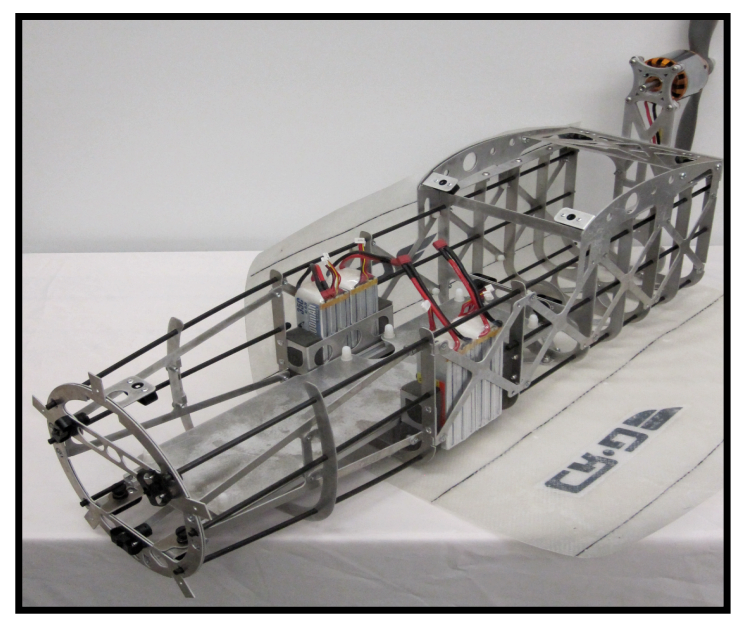

\section{Survey of Student Opinions}

At three times in the project duration surveys were taken of the student's opinion of aspects of the project. One survey was taken early on in the project, another at the end of the Fall term and the other at the end of the Winter term. The final two surveys had repeated questions which allows a comparisons to see changing student opinion. We report here from these last two surveys that had 27 responses at the end of Fall and 30 responses in Winter, both used a six point Likert scale for answering questions.

\subsection{Student Project Interest}

The majority of the students doing this project were undertaking the BEng. Aerospace Engineering program, with the other students coming from Mechanical Eng. (two students), Computer Systems Eng. (three students), Communications Eng. (two students) and Software Eng. (one student). The degree of motivation to undertake a design of an aircraft is not too surprising. Figure 1 shows the the Likert responses at the end of the two terms to the statement "I would prefer to have done a different project". There is strong support throughout the two terms, with a reduction in the 'disagree strongly' category (from $74 \%$ to $67 \%$ ) and a rise in 'agree moderately' (from $0 \%$ to $3 \%$ ) between Fall and Winter.
Besides being a measure of the interest in the project it is also a metric on the quality of the project and its organization and operation.

It should be noted here that the Department has seven team capstone projects and at the end of their third year students are asked to select the three projects, in order of preference, that they would like to work on in their fourth year. All of the students on this project had preselected the UAV project as their first choice in third year.

Figure 1. Responses to "I would prefer to have done a different project"

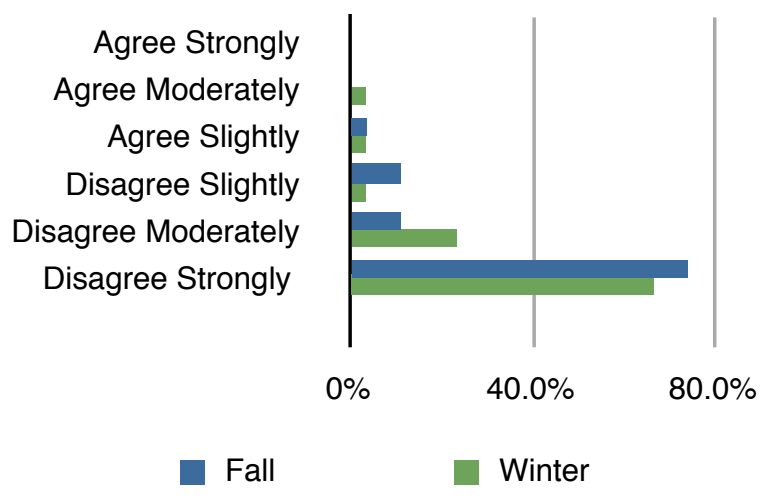

\subsection{Group Organization and Cooperation}

Given the size and number of the groups, plus the number of lead engineers in the whole project team, it was worth examining if the scale of the project was adversely affecting matters. First looking at a group's organization, Figure 3 shows the Likert response distribution to "My group is/was organized" ("is' or 'was' was used depending on the term). The responses show that the majority of students believed their group was organized.

Figure 3. Response to "My group is/was organized"

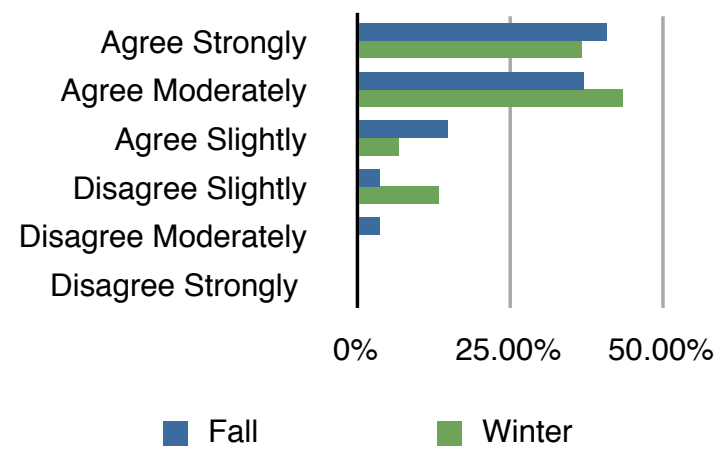

When it came to how well the group worked within itself and with other groups two survey questions were 
posed and the responses are shown in Figures 4 and 5. These show a strong belief the group worked well within itself and also between groups, although the perceived performance within the group appears stronger than across groups.

Figure 4. Responses to "My group worked well together"

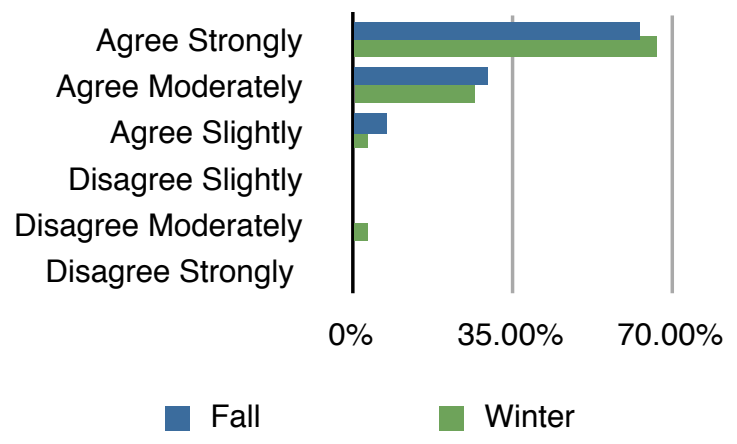

Figure 5. Response to "My group worked well with other groups"

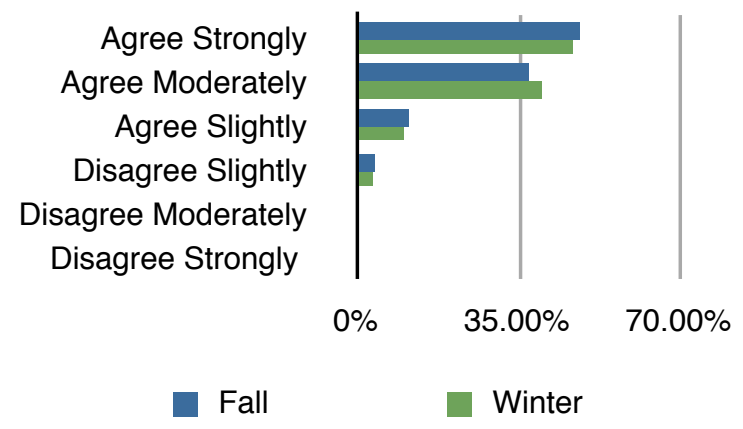

\subsection{Perception of the Type of Work Undertaken}

Although the project contained a significant amount of design work, each individual was assigned a task or tasks and the perception of that work by the individual was assessed in a series of three Likert statements. These asked for an assessment of the amount of design, technical (non-design) and non-technical work that was undertaken. The responses are shown in Figures 6 to 8.

With these three figures we can see the strongest support was for technical work. The response to design work shows a broad distribution with some believing strongly they had done no design work (7\% Fall and 10\% Winter).
For non-technical work there is a strong agreement that this type of work was undertaken. This was probably considered to be report writing, design review preparation and meeting work. It is interesting to note that the 'agree strongly' response rose considerably from the Fall (37\%) to Winter (57\%), which is possibly a reflection of the amount of time and work spent on design reports and final report writing, as well as the final design review, which needed to be completed as the project came to an end.

Figure 6. Responses to "I have been doing design work in the project"

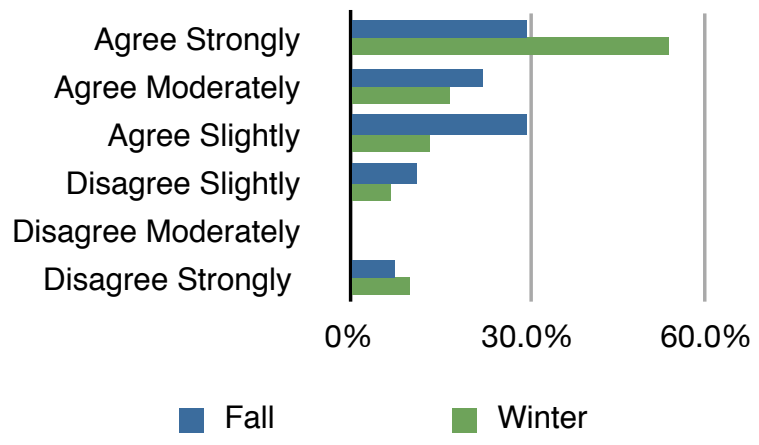

Figure 7. Responses to the question "I did technical (non-design) work in the project"

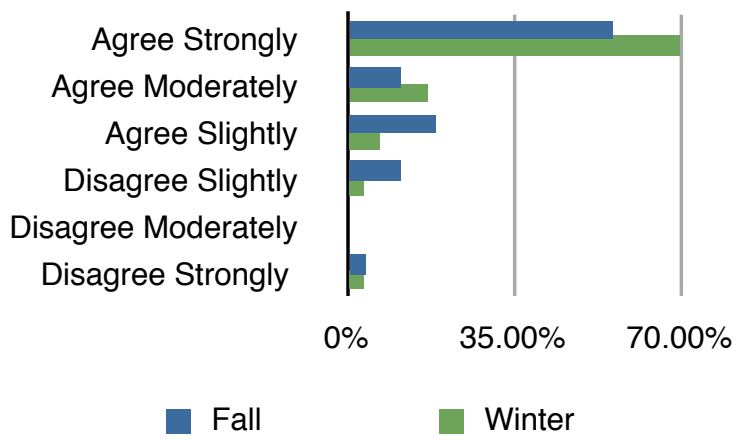

Figure 8. Responses to "I did non-technical work in the project"

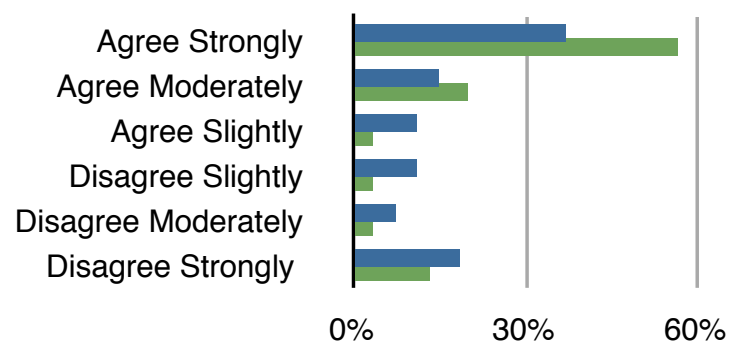




\subsection{Project Burden and Prior Preparation}

Given the project was scheduled to take up a significant amount of time in the academic year, and that the work was open ended, we surveyed the impact of the project on other coursework. The results are shown in Figure 9.

Figure 9. Response to "Participation in this project has negatively affected my ability to complete work in other courses"

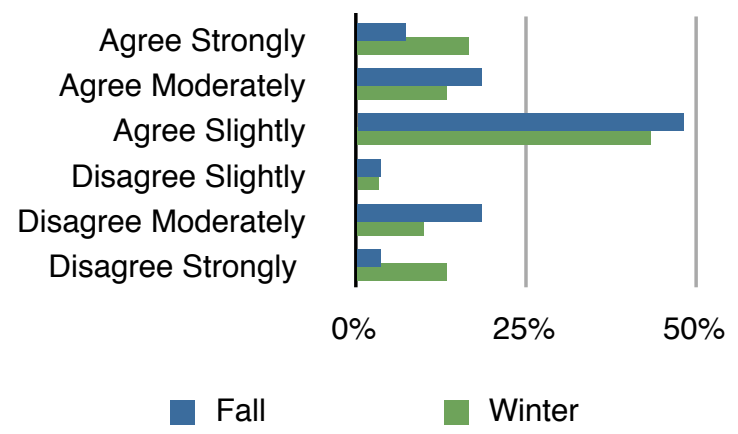

The results in Figure 9 show a spread distribution of results with the median centred on 'agree slightly'. This indicates that most students had the workload under control and perhaps the timesheet helped in controlling this. Careful monitoring of the timesheets by lead engineers and closer feedback may be one way to narrow the distributions spread out to the 'strongly' edges of the survey scale.

Looking at how well prepared students were for the project a single survey question was raised and the results are shown in Figure 10. The results showed that $75 \%$ in Fall and $87 \%$ in Winter agreed they had had adequate course preparation for the project.

Figure 10. Response to "I feel that my prior coursework has adequately prepared me to be successful in the project"

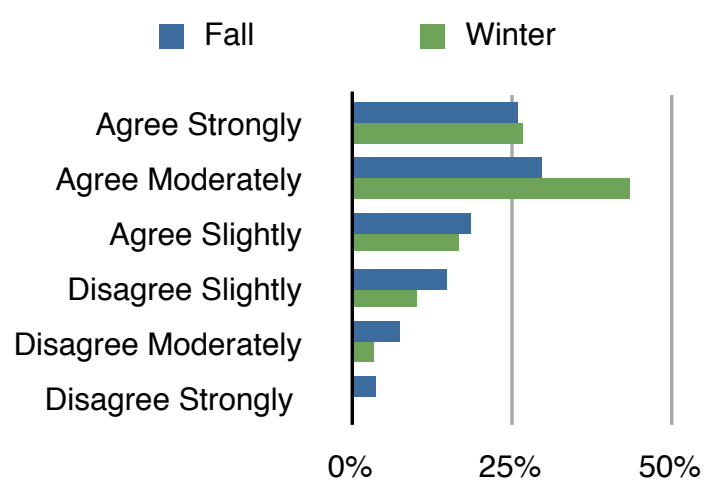

\section{Conclusion}

We have described how a team project with multiple groups can be organized and run to undertake a large scale engineering project. Student surveys show satisfaction with the project and the organization, and for a majority it was not reported as burdensome. Using a project manager and lead engineer model, for the management of such projects, students could be guided to success.

Having larger projects allows the integration of students for different engineering programs. This, combined with the large group size gives the project a closer resemblance to an industrial project. Alongside the technical knowledge used and gained, the students developed extensive communication skills with design reports, weekly meeting presentations and major design reviews. Surveys suggest that self-awareness of this non-technical work was most apparent at the end of the project.

Survey results show students feel that they have undertaken a range of project work, design, technical and non-technical tasks. The widest spread of those was the perception of the involvement with design. There is no doubt that building an aerial vehicle over multi-year, large team projects involves considerable design work. This strongly perceived view, held by a few students, that they had not done any design work is possibly worth further investigation.

\section{References}

[1] Straznicky, P.V., Langlois, R.G., McDill, M., Miller, R., Sjolander, S.A., Staley, D.A.,"Integrated Team Design Projects at Carleton University," Proceedings of the First CDEN International Conference, 2004.

[2] Straznicky, P.V., Kind R.J., "Trends in Aerospace Engineering Education - Meeting the Industry Needs Using a Team Project", Canadian Aeronautics and Space Journal, Vol. 46, No. 2, June 2000.

[3] Richard J. Kind and Paul V. Straznicky, "UAV Design, Development and Testing Activities at Carleton University", UVS Canada Momentum 2003 Conference, Ottawa, November 2003.

[4] Vincent, C., and Wild, P., "Current Practices in Final Year Engineering Design Courses", Proceedings of CDEN, 2007

[5] Laliberte, J. "2010-11 Aircraft Design Project Memorandum”, Internal Document, Dept. of Mechanical and Aerospace Eng., Carleton University, 10th Sept. 2010 